\title{
ASSESSMENT OF RISK FACTORS OF OBESITY AMONG RESIDENTS OF CLASS IV EMPLOYEES' QUARTERS OF A TERTIARY CARE HOSPITAL
}

\author{
Gayatri Birwadkar1, Amandeep Kaur Ratta²
}

1 Junior Associate, Syngience, India.

${ }^{2}$ Senior Programme Officer, Jhpiego, India.

\author{
BACKGROUND \\ There is very little information available on various risk factors responsible for obesity among class IV workers working in a health \\ institute. Present study was conducted to assess the risk factors of obesity among residents of Class IV employees' quarters of a \\ tertiary care hospital.
}

ABSTRACT

\section{METHODS}

This was cross sectional study carried out in a practice field area of tertiary care hospital. Study population was adults (male and female) between ages of 30 years to 59 years. Approval from the institutional ethics committee was taken.

\section{RESULTS}

On analysis, excess calorie intake was found to be a significant risk factor for overweight/obesity $(\mathrm{OR}=3.00,95 \% \mathrm{CI} 1.47-6.138$, $\mathrm{p}=0.0022)$. Intake of non-vegetarian diet for $\geq 3$ days was not found to be significant risk factor for overweight $/ \mathrm{obesity}\left(\mathrm{x}^{2}=0, \mathrm{df}=\right.$ $1, \mathrm{p}=0$ ). On analysis, more intake of junk food i.e., for $\geq 3$ days was found to be a significant risk factor for overweight $/$ obesity $\left(x^{2}=\right.$ $27.39, \mathrm{df}=1, \mathrm{p}<0.0001)$. Not doing any exercise was found to be a significant risk factor for overweight $/$ obesity $\left(x^{2}=8.958, d f=1\right.$, $\mathrm{p}=0.0028)$.

\section{CONCLUSIONS}

Excess of calorie intake, intake of junk food i.e. for $\geq 3$ days, not doing any exercise and hypertension were found to be significantly associated with overweight/obesity.

\section{KEY WORDS}

Risk Factor, Obesity, Junk Food, Exercise, Calorie

HOW TO CITE THIS ARTICLE: Birwadkar G, Ratta AK. Assessment of risk factors of obesity among residents of class IV employees' quarters of a tertiary care hospital. J. Evolution Med. Dent. Sci. 2019;8(29):2367-2370, DOI: 10.14260/jemds/2019/518

\section{BACKGROUND}

Excess abdominal fat is an independent predictor of the risk factors and the morbidity of obesity related diseases such as type 2 diabetes, hypertension, dyslipidaemia and cardiovascular diseases. The Waist Circumference (WC) is positively correlated with the abdominal fat. Hence, the waist circumference is a valuable, convenient and a simple measurement method which can be used for identifying the individuals who are at an increased risk for the above mentioned diseases. ${ }^{1}$

Studies from Western countries suggest that vegetarian diets may have a protective role against the development of obesity and diabetes. The European Prospective Investigation Study (EPIC-Oxford) found that mean BMI (Body Mass Index) was highest in meat-eaters, lowest in vegans, and intermediate in fish-eaters and vegetarians. ${ }^{2}$ Within this, there is little information on whether the vegetarian diet confers a similar protective effect against obesity and diabetes that have been demonstrated in western studies. ${ }^{2}$

'Financial or Other Competing Interest': None.

Submission 20-05-2019, Peer Review 04-07-2019,

Acceptance 11-07-2019, Published 22-07-2019.

Corresponding Author:

Dr. Amandeep Kaur Ratta,

\#29, Jhpiego India Country Office,

Okhala Industrial Estate,

Okhala Phase 3, New Delhi-110020

India.

E-mail: drpatilyogesh1985@gmail.com

DOI: 10.14260/jemds/2019/518
Unfavourable SES and poor lifestyles were associated with risk of obesity, with greater impact on WC than BMI, especially in middle-aged men. ${ }^{3}$ Number of class IV workers coming in low socioeconomic status. Keeping all this scenario in mind, the present study was conducted to do assessment of risk factors of obesity among residents of Class IV employees' quarters of a tertiary care hospital.

\section{METHODS}

Study Design

Cross sectional study.

\section{Study Area}

Class IV employees' quarters of a tertiary health care hospital in a metropolitan city.

\section{Study Population}

Adults (Male and Female) between ages of 30 years to 59 years.

\section{Duration of Study}

6 months (July 2014 to Jan. 2015)

\section{Sample Size}

144.

$[\mathrm{n}=4 \mathrm{pq} \div \mathrm{L} 2, \mathrm{p}=10 \& \mathrm{~L}=5 \%]^{4}$

\section{Research Tool}

A semi-structured questionnaire. 


\section{RESULTS}

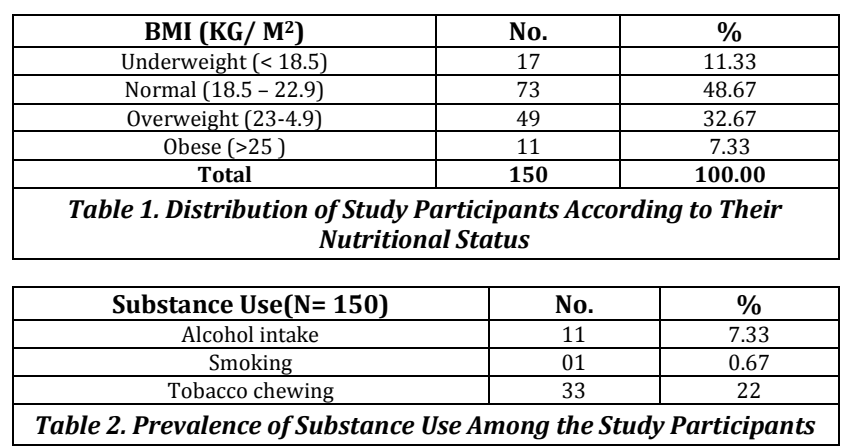

\begin{tabular}{|c|c|c|c|}
\hline Risk Factor & $\begin{array}{l}\text { Overweight/ } \\
\text { Obese N (\%) }\end{array}$ & \begin{tabular}{|c|} 
Non-Obese \\
N (\%) \\
\end{tabular} & $\begin{array}{c}\mathbf{p} \\
\text { Value }\end{array}$ \\
\hline \multicolumn{4}{|l|}{ Total calorie intake per day } \\
\hline More than Recommended & $45(75)$ & $45(50)$ & \multirow{2}{*}{0.0022} \\
\hline Recommended or less & $15(25)$ & $45(50)$ & \\
\hline \multicolumn{4}{|l|}{ Fruits intake/ week } \\
\hline$\geq 4$ & $30(50)$ & $37(41.11)$ & \multirow{3}{*}{0.59} \\
\hline $2-3$ & $15(25)$ & $32(35.56)$ & \\
\hline$\leq 1$ & $15(25)$ & $21(23.33)$ & \\
\hline \multicolumn{4}{|l|}{$\begin{array}{c}\text { Green leafy vegetables } \\
\text { intake/ week }\end{array}$} \\
\hline$\geq 4$ & $35(58.33)$ & $59(65.56)$ & \multirow{3}{*}{0.60} \\
\hline $2-3$ & $23(38.34)$ & $26(28.88)$ & \\
\hline$\leq 1$ & $02(3.33)$ & $05(5.56)$ & \\
\hline \multicolumn{4}{|l|}{ Non-vegetarian diet/ week } \\
\hline$\geq 3$ & $34(56.67)$ & $53(58.89)$ & \multirow{2}{*}{$<0.001$} \\
\hline$\leq 2$ & $26(43.33)$ & $37(41.11)$ & \\
\hline \multicolumn{4}{|l|}{ Junk food/ week } \\
\hline$\geq 3$ & $20(33.33)$ & $05(5.56)$ & \multirow{2}{*}{$<0.01$} \\
\hline$\leq 2$ & $40(66.67)$ & $85(94.44)$ & \\
\hline \multicolumn{4}{|c|}{$\begin{array}{c}\text { Table 3A. Distribution of Study Subjects According to Risk Factors } \\
\text { and Obesity }\end{array}$} \\
\hline
\end{tabular}

\begin{tabular}{|c|c|c|c|}
\hline Risk Factors & $\begin{array}{c}\text { Overweight/ } \\
\text { Obese }\end{array}$ & Non-Obese & $\begin{array}{c}\mathbf{p} \\
\text { Value }\end{array}$ \\
\hline \multicolumn{4}{|l|}{ Exercise } \\
\hline Mild & $52(86.67)$ & 55 (61.11) & \multirow[b]{2}{*}{$<0.01$} \\
\hline Moderate & 08 (13.33) & 35 (38.89) & \\
\hline \multicolumn{4}{|l|}{ Hypothyroidism } \\
\hline Present & $04(6.67)$ & $06(6.67)$ & \multirow[b]{2}{*}{0.87} \\
\hline Absent & $56(93.33)$ & $84(93.33)$ & \\
\hline \multicolumn{4}{|l|}{ Hypertension } \\
\hline Present & $30(50)$ & $20(22.22)$ & \multirow[b]{2}{*}{$<0.01$} \\
\hline Absent & $30(50)$ & $70(77.78)$ & \\
\hline \multicolumn{4}{|l|}{ Diabetes } \\
\hline Present & $06(10)$ & $06(6.66)$ & \multirow[b]{2}{*}{0.46} \\
\hline Absent & $54(90)$ & $84(93.34)$ & \\
\hline \multicolumn{4}{|c|}{$\begin{array}{c}\text { Table 3B. Distribution of Study Subjects According to Risk Factors, } \\
\text { Comorbidities and Obesity }\end{array}$} \\
\hline
\end{tabular}

\section{Pilot Study}

The questionnaire was tested on few study participants and that data were not included in final analysis. The necessary changes in the questionnaire were made based on the pilot study.

\section{Consent and Ethics Approval}

This study was beginning after approval from the institutional ethics committee. Informed written\& valid consent from all the participants were taken before enrolling them in the study. Confidentiality of the study participants was maintained.

\section{Methodology}

The present study was undertaken in Class IV employees' quarters of a tertiary health care hospital and the households in Class IV employees' quarters were sampled by a systematic random sampling method. A semi-structured questionnaire was used to collect the information regarding Personal history, Dietary history, and Disease were collected by using a questionnaire. The waist circumference was measured at the midpoint between the lower border of the rib cage and the iliac crest by using a flexible inch tape and hip circumference was measured around the widest portion of the buttocks, with the tape parallel to the floor. As per the WHO the following cut off values of the waist-hip ratio were used to assess the abdominal obesity: - waist-hip ratio above 0.90 for males and above 0.85 for females. Body mass index was calculated as weight $(\mathrm{kg})$ divided by squared height $(\mathrm{m})$. Measuring cup was used for measuring volume of tea for calorie purpose.

\section{Statistical Analysis}

The data entry was made in the Excel software and the analysis was done by using the Statistical Package for Social Science (SPSS), version 20.

Table 1 shows distribution of study participants according to their nutritional status. nutritional status was assessed by measuring Body Mass Index (BMI). Criteria given by WHO were used to measure the nutritional status of study participants.Of the 150 study participants, $11(7.33 \%)$ gave history habit of alcohol intake. All of them were males. Only one study participant was a smoker and was a female. Most common substance use i.e. $33(22 \%)$, found among the study participants was tobacco chewing. Table 3A shows association of overweight/ obesity with excess of calorie intake on analysis, excess of calorie intake was found to be a significant risk factor for overweight/ obesity (OR=3.00, 95\% CI $1.47-6.138, p=0.0022$ ). Table $3 \mathrm{~A}$ shows association of overweight/ obesity with consumption of fruits. On analysis, there was no significant trend seen in less intake of fruits and overweight/ obesity ( $x^{2}$ for trend $=0.2916, d f=1, p=0.5892$ ). Table 3A shows association of overweight/ obesity with consumption of green leafy vegetables. On analysis, there was no significant trend seen in less intake of green leafy vegetables and overweight/ obesity $\left(\mathrm{x}^{2}\right.$ for trend $=0.2671, \mathrm{df}=$ $1, p=0.6053$ ). Table $3 \mathrm{~A}$ shows association of overweight/ obesity with frequency of intake of non-vegetarian diet. On analysis, intake of non-vegetarian diet for $\geq 3$ days was not found to be significant risk factor for overweight/ obesity $\left(x^{2}=0, d f=1, p=0\right)$. Table $3 \mathrm{~A}$ shows association of overweight/ obesity with frequency of having junk food. On analysis, mor intake of junk food i.e., for $\geq 3$ days was found to be a significant risk factor for overweight/ obesity $\left(x^{2}=\right.$ 27.39, $\mathrm{df}=1, \mathrm{p}<0.0001$ ).

Table 3B shows association of overweight/ obesity with exercise. Of the 60 overweight or obese study participants, only $08(13.33 \%)$ were doing daily exercise for at least 30 minutes Majority 52 (86.67\%) were not doing any routine exercise. Of the 90 non-obese study participants, 35 (38.89\%) were doing daily exercise for at least 30 minutes. 55 $(61.11 \%)$ were not doing any routine exercise. On analysis, not doing any exercise was found to be a significant risk factor for overweight/ obesity $\left(x^{2}=8.958, d f=1, p=0.0028\right)$. Table 3B shows association hypothyroidism with obesity. Of the total 150 study participants, only 10 were the diagnosed cases of hypothyroidism. Of the 60 overweight or obese study participants, only $04(6.67 \%)$ were diagnosed cases of hypothyroidism. Of the 90 non-obese study participants, only $06(6.67 \%)$ were \%) were diagnosed cases of hypothyroidism. On analysis, hypothyroidism was not found 
to be a significant risk factor for overweight/ obesity ( $x^{2}=$ $0.02844, \mathrm{df}=1, \mathrm{p}=0.8661$ ).

Of the 50 study participants who were known cases of hypertension, $30(60 \%)$ were overweight/ obese and 20 (40\%) were non-obese. Of the 100 study participants who were not known cases of hypertension, 30 (30\%) were overweight/ obese and 70 (70\%) were non-obese. On analysis, overweight/ obesity was found to be a significant risk factor for hypertension $\left(x^{2}=12.50, d f=1, p=0.0004\right)$. Only 12 study participants gave the history of diabetes mellitus diagnosed with investigations. Of them, 06 (50\%) were overweight/ obese and $06(50 \%)$ were non-obese. Of the 138 study participants who did not give the history of diabetes mellitus, 54 (39.13\%) were overweight/ obese and $84(60.87 \%)$ were non-obese. On analysis, overweight/ obesity was not found to be a significant risk factor for diabetes $\left(x^{2}=0.5435, d f=1, p=0.4610\right)$.

\section{DISCUSSION}

In present study there was distribution of study participants according to their nutritional status. Nutritional status was assessed by measuring Body Mass Index (BMI).Criteria given by WHO were used to measure the nutritional status of study participants. Følling et al $(2014)^{5}$ conducted cross-sectional study and found that the mean BMI for the total sample at screening was $25.4 \mathrm{~kg} / \mathrm{m}^{2}$. The general characteristics (age, height, weight and BMI) of the male and female patients studied according to somatic and psychiatric departments. Gupta R at el $(2012)^{6}$ conducted cross-sectional studies among adult (male and female) between age of 20-59 years in urban populations in Jaipur and Delhi. They found that there is a significant linear association of multiple cardiovascular risk factors with BMI. This is confirmed by linear regression, quadratic regression, and non-linear analyses. Body mass index was correlated significantly with weight $(0.80,0.64)$. Dua S et al $(2014)^{7}$ conducted cross-sectional study. BMI and fat percentage were calculated. BMI was classified according to the proposed criteria of World Health Organisation (WHO).BMI is most widely used to estimate the prevalence of obesity or underweight within a population. Of the 150 study participants, $11(7.33 \%)$ gave history habit of alcohol intake. All of them were males. Only one study participant was a smoker and was a female. Most common substance use i.e., 33 (22\%), found among the study participants was tobacco chewing.

Agrawal S et al (2014) ${ }^{8}$ conducted cross sectional study. $19(1.8 \%)$ of women participants gave history of smoking and $323(31.2 \%)$ of men participants gave history of smoking. 1 $(0.1 \%)$ of women participants gave history of alcohol intake and $59(5.7 \%)$ of men gave history of alcohol intake.

In our study of the 60 overweight or obese study participants, $45(75 \%)$ consumed more than recommended total calorie intake per day according to the 24-hour recall method. Of the 90 non-obese study participants, 45 (50\%) consumed more than recommended total calorie intake per day according to the 24-hour recall method. On analysis, excess of calorie intake was found to be a significant risk factor for overweight/ obesity $(\mathrm{OR}=3.00,95 \%$ CI 1.47 $6.138, p=0.0022)$. Kim SH et al $(2012)^{9}$ conducted crosssectional study and found that for analysis of the association between nutrient intake and obesity. 1,887.2 \pm 415.8 obese men consume more than recommended total calorie intake and 1,854.8 \pm 391.0 non-obese men consume more than recommended calorie intake $(\mathrm{p}=015)$. And 1,612.8 \pm 413.2 obese women consume more calorie than recommended and $1,617.8 \pm 395.8$ non-obese women consume more calorie than recommended $(\mathrm{p}=0.80)$

In present study of the 60 overweight or obese study participants, $30(50 \%)$ study participants used to consume fruits for $\geq 4$ days per week, 15 (25\%) for 2- 3 days and 15 (25\%) for $\leq 1$ day per week. Of the 90 non-obese study participants, 37 (41.11\%) study participants used to consume fruits for $\geq 4$ days per week, 32 (35.56\%) for 2 - 3 days and 21 $(23.33 \%)$ for $\leq 1$ day per week. On analysis, there was no significant trend seen in less intake of fruits and overweight/ obesity ( $x^{2}$ for trend $=0.2916, \mathrm{df}=1, \mathrm{p}=0.5892$ ). Hazzaa M AlHazzaa et al (2012) ${ }^{10}$ conducted cross-sectional study among adolescent [aged 14-19 years] males and females. Of the total participants $3.40 \pm 2.4$ overweight male participants used to consume fruits and $3.16 \pm 2.3$ obese male participants used to consume fruits. $2.71 \pm 2.2$ overweight female participants used to consume fruits and $2.51 \pm 2.1$ obese male participants consume fruits. $(p=0.05)$

In our study of the 60 overweight or obese study participants, 35 (58.33\%) study participants used to consume green leafy vegetables for $\geq 4$ days per week, 23 (38.34\%) for 2 - 3 days and $02(3.33 \%)$ for $\leq 1$ day per week. Of the 90 nonobese study participants, $59(65.56 \%)$ study participants used to consume green leafy vegetables for $\geq 4$ days per week, 26 (28.88\%) for $2-3$ days and 05 (5.56\%) for $\leq 1$ day per week. On analysis, there was no significant trend seen in less intake of green leafy vegetables and overweight/ obesity $\left(x^{2}\right.$ for trend $\left.=0.2671, d f=1, p=0.6053\right)$. Agrawal $S$ et al $(2011)^{8}$ conducted cross-sectional study. Among study participants 538 (51.3\%) women consume green leafy vegetables daily and $107(10.3 \%)$ men consume green leafy vegetables daily [ $\mathrm{p}=0.001]$.and $360(34.3 \%)$ women consume green leafy vegetable weekly and $346(33.4 \%)$ men consume green leafy vegetable weekly. $[\mathrm{P}=0.001]$

In present study we showed association of overweight/ obesity with frequency of intake of non-vegetarian diet. Of the 60 overweight or obese study participants, 34 (56.67\%) used to take non-vegetarian diet for $\geq 3$ days per week and 26 $(43.33 \%)$ for $\leq 2$ days/ week. Of the 90 non-obese study participants, 53 (58.89\%) used to take non-vegetarian diet for $\geq 3$ days per week and 37 (41.11\%) for $\leq 2$ days/ week. On analysis, intake of non-vegetarian diet for $\geq 3$ days was not found to be significant risk factor for overweight/ obesity $\left(x^{2}=0 ., d f=1, p=0\right)$. Sharma D et al $(2012)^{11}$ conducted A cross-sectional survey among AIIMS administrative employees (Group A, B and C) and their family members aged 30 years or above. Among all participants 211 (46.6\%) were non-vegetarian.

In our study of the 60 overweight or obese study participants, 20 (33.33\%) used to have junk food for $\geq 3$ days per week and $40(66.67 \%)$ for $\leq 2$ days/ week. Of the 90 nonobese study participants, 05 (5.56\%) used to have junk food for $\geq 3$ days per week and 85 (94.44\%) for $\leq 2$ days/ week. On analysis, more intake of junk food i.e. for $\geq 3$ days was found to be a significant risk factor for overweight/ obesity $\left(x^{2}=27.39, \mathrm{df}=1, \mathrm{p}<0.0001\right)$. Hazzaa M Al-Hazzaa et al $(2012)^{10}$ conducted cross-sectional. $3.40 \pm 2.4$ overweight male used to have junk food and $3.16 \pm 2.3$ obese male used to have junk food. And $2.71 \pm 2.2$ overweight female used to 
have junk food in their diet and $2.51 \pm 2.1$ obese female used to have junk food in their diet. $(\mathrm{P}=0.05)$

In present study of the 60 overweight or obese study participants, only $08(13.33 \%)$ were doing daily exercise for at least 30 minutes. Majority 52 (86.67\%) were not doing any routine exercise. Of the 90 non-obese study participants, 35 (38.89\%) were doing daily exercise for at least 30 minutes. $55(61.11 \%)$ were not doing any routine exercise. On analysis, not doing any exercise was found to be a significant risk factor for overweight/ obesity $\left(x^{2}=8.958, \mathrm{df}=1, \mathrm{p}=\right.$ 0.0028). Sharma D et al (2012) ${ }^{11}$ conducted A cross-sectional survey among AIIMS administrative employees (Group A, B and $C$ ) and their family members aged 30 years or above. 127 (50.6\%) men doing regular physical activity and 124 (49.4) were not doing regular physical activity. And 146 (72.3\%) women doing regular physical activity and 56 (27.7\%) women not doing regular physical activity. $(p=0.001)$.

Of the 50 study participants who were known cases of hypertension, 30 (60\%) were overweight/ obese and 20 $(40 \%)$ were non-obese. Of the 100 study participants who were not known cases of hypertension, 30 (30\%) were overweight/ obese and 70 (70\%) were non-obese. On analysis, overweight/ obesity was found to be a significant risk factor for hypertension $\left(x^{2}=12.50, d f=1, p=0.0004\right)$. Anchalaa $R$ et al (2014) ${ }^{12}$ conducted cross sectional study and found that Overall prevalence for hypertension in India was 29.8\% (95\% confidence interval: 26.7-33.0). Significant differences in hypertension prevalence were noted between rural and urban parts [27.6\% (23.2-32.0) and 33.8\% (29.737.8); $\mathrm{P}=0.05]$.They also found that higher prevalence of HTN in urban areas may have arisen as cardiovascular disease risk factors among the urban poor and middle class are rapidly increasing in India. Lifestyle changes (harmful dietary practices, consumption of tobacco, and sedentary habits) occurring because of rapid urbanization and economic progress in urban areas has also contributed to the growing epidemic of HTN in urban areas of India.

Only 12 study participants gave the history of diabetes mellitus diagnosed with investigations. Of them, 06 (50\%) were overweight/ obese and 06 (50\%) were non-obese. Of the 138 study participants who did not give the history of diabetes mellitus, 54 (39.13\%) were overweight/ obese and $84(60.87 \%)$ were non-obese. On analysis, overweight/ obesity was not found to be a significant risk factor for diabetes $\left(x^{2}=0.5435, d f=1, p=0.4610\right)$. Agrawal $S$ et al $(2011)^{8}$ conducted cross sectional study and found that Prevalence of diabetes was 1054/100 000 (95\% CI 974, 1134) among women and 1598/100, 000 (95\% CI 1462, 1735) among men in India. Diabetes was more common among both women and men who consumed milk or curd, eggs, fish, chicken or meat daily, who were either overweight or obese. They also found that Diabetes was three times higher among obese women (OR53.05; 95\% CI 2.49, 3.73) and 1.5 times higher among obese men (OR51.49; 95\% CI $1.06,2.08)$.

\section{CONCLUSIONS}

Excess of calorie intake, intake of junk food i.e. for $\geq 3$ days, not doing any exercise and hypertension were found to be significantly associated with overweight/obesity in Class IV Employees' Quarters of a Tertiary Care Hospital.

\section{REFERENCES}

[1] Anuradha R, Hemachandran S, Ruma D. The waist circumference measurement: a simple method for assessing the abdominal obesity. Journal of Clinical and Diagnostic Research 2012;6(9):1510-13.

[2] Agrawal S, Ebrahim S. Prevalence and risk factors for self-reported diabetes among adult men and women in India: findings from a national cross-sectional survey. Public Health Nutrition 2012;15(6):1065-77.

[3] Han TS, Lee DM, Lean MEJ, et al. Associations of obesity with socioeconomic and lifestyle factors in middle-aged and elderly men: European Male Aging Study (EMAS). Eur Soc Endocrinol 2015;172(1):59-67.

[4] Grijalva-Eternod CS, Wells JC, Cortina-Borja N, et al. The double burden of obesity and malnutrition in a protracted emergency setting: a cross-sectional study of Western Sahara refugees. PLoS Med 2012;9(10):e1001320.

[5] Følling IS, Kulseng B, Helvik AS. Overweight, obesity and related conditions: a cross-sectional study of adult inpatients at a Norwegian hospital. BMC Research Notes 2014;7:115.

[6] Gupta R, Agrawal A, Misra A, et al. Metabolic cardiovascular risk factors worsen continuously across the spectrum of body mass index in Asian Indians. Indian Heart Journal 2012;64(3):236-44.

[7] Dua S, Bhuker M, Sharma P, et al. Body mass index related to blood pressure among adults. N Am J Med Sci 2014;6(2):89-95.

[8] Agrawal S, Millett CJ, Dhillon PK, et al. Type of vegetarian diet, obesity and diabetes in adult Indian population. Nutrition Journal 2014;13:89.

[9] Kim SH, Hong SB, Suh YJ, et al. Association between nutrient intake and obesity in type 2 diabetic patients from the Korean National Diabetes Program: a crosssectional study. J Korean Med Sci 2012;27(10):118895.

[10] Al-Hazzaa HM, Abahussain NA, Al-Sobayel HI, et al. Lifestyle factors associated with overweight and obesity among Saudi adolescents. BMC Public Health 2012;12:354.

[11] Sharma D, Vatsa M, Lakshmy R, et al. Study of cardiovascular risk factors among tertiary hospital employees and their families. Indian Heart Journal 2012;64(4):356-63.

[12] Anchala R, Kannuri NK, Pant H, et al. Hypertension in India: a systematic review and meta-analysis of prevalence, awareness and control of hypertension. Journal of Hypertension 2014;32(6):1170-7. 